information on areas to modify and education areas to target in 2012 .

\title{
88 THE PRIMARY CARE PALLIATIVE CARE PROGRAMME IN AUCKLAND, NEW ZEALAND: AN UPDATE
}

S Rishworth', D Winstanley ${ }^{1}$ Mercy Hospice Auckland; ${ }^{2}$ Procare Primary Health Organisation (Auckland); ${ }^{3}$ Auckland District Health Board; ${ }^{4}$ Waitemata District Health Board

10.1136/bmjspcare-2012-000250.85

The PCPCP has been implemented amongst GP teams in Procare, a Primary Health Organisation (PHO) in Auckland, New Zealand. Implementation began two years ago and in that time 412 patients have been enrolled in the programme with 288 general practitioners (GPs) and practices nurses having attended the compulsory two hour introduction to the programme. The programme has been evaluated in a formal study which included face to face interviews and a questionnaire. The results have been valuable in ascertaining what has been helpful and what needs modification. The most appreciated aspects include the subsidy available for the one hour consultation and subsequent patient contacts, the advance care planning and assessment templates and the education resources made available. It became clear that the use of other components was limited by misunderstandings of their purpose. These components included a patient register for the practice, an after death analysis form and a prognostic indicator guide. On line education resources had variable uptake. Easy access to a Palliative Medicine Consultant for discussion of individual patients and a palliative care handbook provided to each participating GP/practice nurse were valued. The evaluations demonstrated that the PCPCP initiative was appreciated and supported by GP teams who liked the collaborative approach and the affirmation of the role of GP teams as the coordinators and providers of palliative care in the community. It has given 